\title{
STUDENTS PERCEPTION ABOUT THE ROLE OF INTERVIEW DURING M.PHIL AND PH.D. ADMISSION AT A PUBLIC SECTOR UNIVERSITY OF LAHORE, PUNJAB-PAKISTAN
}

\author{
Muhammad Adnan Maqbool ${ }^{1^{*}}$, Aroona Hashmi ${ }^{2}$, Mehboob Ul Hassan ${ }^{3}$, Fasiha Altaf ${ }^{4}$ \\ ${ }^{1 *}$ University of Education, Attock Campus, Attock-Pakistan; ${ }^{2,3,4}$ Institute of Education and Research, University of the \\ Punjab, Lahore, Punjab, Pakistan. \\ Email: ${ }^{1 *}$ adnanmaq@gmail.com, ${ }^{2}$ aroona.ier@pu.edu.pk, ${ }^{3}$ hassanbhattig@ hotmail.com, ${ }^{4}$ fasihashah@ hotmail.com
}

Article History: Received on $5^{\text {th }}$ July 2021, Revised on $22^{\text {nd }}$ July 2021, Published on $27^{\text {th }}$ July 2021

\begin{abstract}
Purpose of the Study: Focusing on the importance of the research interview, the researchers planned current qualitative research to explore students' perceptions about the role of an interview conducted during the selection of M.Phil and Ph.D. admission in one of the public sector University of Lahore, Punjab-Pakistan.

Methodology: The researchers adopted qualitative research leading to interpretivism paradigm. This study adopted a phenomenology research design. The researchers selected five M.Phil and five Ph.D. scholars were selected by using purposive technique. The researchers administered a self-constructed interview protocol to collect the data from the respondents. After signing a formal consent letter from participants, the researchers recorded interviews from the respondents in voice recorders and transcribed the interviews word by word. The researchers used thematic analysis approach to analyze the data.
\end{abstract}

Main Findings: The results declared that the majority of the students agreed that personality has a better effect during the interview; slight sensation of nervousness before the interview; disturbed bodily condition before interview panel; friendly, cooperative, and supportive behaviour of interview panel; comfortable environment; enriched institute with qualified foreign faculty; fully confident after the interview for admission; asking of relevant questions and they get admission in to enhance their qualification for getting good-paying job and knowledge.

Applications of this study: The results of the current research are applicable in public and private sector universities of Punjab, including district Lahore in which experiential and dynamic teachers are the members of the selection panel. They were aware of students perceptions while conducting interviews and familiar with their exact situations that happened in the committee rooms, as the students/applicant are the real observe of their teachers.

Novelty/Originality of this study: This is the innovative and foremost research structured in Pakistani public sector educational institutions in which the authors highlighted the actual situations that happened between the interviewer and the interviewee during M.Phil and Ph.D admission. The authors have also contributed to the existing body of knowledge. The findings of the research have opened the horizon for future researchers to explore the dimension of the interviews focusing on the quantitative and mix-method design on a large sample of the participants.

Keywords: Interview Approaches, Research Interview, Interview Styles, Interview Types.

\section{INTRODUCTION}

The research interview is a multi-dimensional way of exchanging information for the prescribed purposes. The interview panels apply this fundamental technique to select dynamic, self-motivated, and energetic participants. After facing multiple personalities, the panels justify that whether the concerned respondents/interviewee is applicable for the current/required post/admission or not. The research interview is a key source of information that principally understands from the researchers' vision. Interview refers to a formal conversation between an applicant and candidate in which both exchange information deliberately in a limited period for a specific purpose. Both have the intention to achieve their targets as per the given criteria (Adhabi \& Anozie, 2017). An important criterion in educational institutions is selection. It is the procedure that involves choosing an appropriate applicant to fill the position (Isham et al., 2021). Many procedures are followed by institutions for students selections to get enrolled for a higher degree. Among these procedures, the interview is one of the pivotal ways that is used by the competent authorities to access and estimate the actions of applicants to make sure the fair process (Silverman, 2020). The procedure is essential as it spends time planning as it may assist the interviewee in picking the right applicant for admission (Deterding \& Waters, 2021; Robinson, 2014). The interview is the most critical aspect of the selection process of the degree programme. The interviews are batteries in the assessment of tools. They are realistic and flexible and can be brought into play at diverse phases throughout the selection process. The interviews also provide an option for the applicants to structure their consciousness on their potentials (Rosinger et al., 2021). The interviews dole out the essential foundation of auxiliary information from the applicants. They provide roots in evaluating basic data abilities, talent, and attitude of any applicant towards their interest in any higher degree. Then it makes a decision that the concerned applicant is capable of being further, admitted, or eliminated from consideration (Ho et al., 2021; Pachana et al., 2006; Sonnentag et al., 2021).

The important method in qualitative research is the representation of interviews, as it is an effective way for data collection. They make available for the researchers with opportunities and rich data ( $\mathrm{Li}, 2021$; Warren, 2002). 
Particularly, interviews present constructive methodologies in gaining information about individuals perceptions (Beitin, 2008). Interviews are the main operational technique in qualitative research methodologies (Canagasuriam \& Roulin, 2021; Hewitt et al., 2021; Shahvaroughi et al., 2021). There is enormous diversity in the designation and execution of interview selection. Interviews differ in terms of arrangement, structure, modes of styles, time management, evaluation of applicants responses, and their content of interview (Hamidi et al., 2021). They are designed to incorporate the interviewer as an applicant eyewitness, even though the remaining is more objective and resemblance to communication tests. Execution and designation of the interview methods have a diverse impact on its validity, reliability, and fairness (Fauber, 2006). The interview used as a tool in the process of selection/enrollment for applicants in many research degree programs has been focused greatly criticized over time (Rosinger et al., 2021). However, it has been still maintained its significance in its usage. In every walk of life, especially in an educational institution, the interviews have been a long history in the selection process for suitable applicants, especially in the research-oriented (Schudlik et al., 2021). Queries of interviews on its values, ethics, and morals in selecting applicants have been lifted (Weston et al., 2021). During conducting the interview, the panel observed many self-evident mistakes of the suitable applicant for admission (Mohamadi et al., 2021). Fundamental development towards the usage of an interview for the selection of applicants has been made obvious as the interviews can be valid if they are properly conducted within a set paradigm (Melinder et al., 2021; Postuma et al., 2002). The process of an interview is remarkably more incomplete, with most research dealing with internships and not the selection of applicants in many of the degree programs (Bakker et al., 2019; Hewitt et al., 2021; Mittenberg et al., 2000; Rotteveel et al., 2021; Smith et al., 2021; Yusoff, 2019). Lopez et al. (1996) surveyed 115 interviews of directors that were the second frequently used selection method for applicants. Results declared that the interviews are an important worldwide method of selection in organizations.

Interviews are of four styles; the situational interviews style is strong-minded that how the response of the interviewee actual works according to situations (Heimann et al., 2020). This situation is mainly measured via role-playing, solution of factual issues, or hypothetically taking part. The personality interviews style estimates the significance of the success of any applicant regarding the position. It mainly focuses on the evaluation of the personality of the interviewee (Bourdage et al., 2021; Di Pierro et al., 2020). The stress interviews style measures the abilities of any applicant when they are facing a highly stressful situation. The interview panel analyzes the candidates potential on behalf of the applicants knowledge, skills, and confidence (Frost et al., 2020). The behavioural interviews style focuses on past performance concerning personality. During the interviewee, the panel concentrate on the applicant's past educational evidence, practical performances, and behavioural situations, predict hidden potential, and recommends that the participant is suitable for the said position or not (Krajewski et al., 2006; Rad \& Balas, 2020).

The interviews are categorized as structured, semi-structured, and unstructured interviews. The structured interview mainly focuses on pre-planned problems and issues. Whereas few interviewers inquire questions in a sequence, while remaining are in relax approach, both have a centre of attention on pre-planned questions (Isham et al., 2021; Rosinger et al., 2021; Smith et al., 2021). The structured interviews protect besides discrimination in selection or rejection as it suggested asking the same questions from the applicants (Seldman, 2012). The validity of the interviewee confirmed through structured interviews occurs from the rivalling position of sight during specific degree programs ( $\underline{\text { Holt } \&}$ Hughes, 2021). Literature reports that no less than fifteen aspects might be integrated to enlarge the structured interviews (Kwan et al., 2021). A semi-structured interview contains the questions of direction or an inventory of different items arranged in a sequence to facilitate throughout the interview process (Onwuegbuzie et al., 2008). The guider has consent to neglect items that were previously answered and inquired additional items/questions in the struggle to probe for a further mode of information (Tingaz, 2021). There is no need to plan specific questions and answers from any applicants (Di Pierro et al., 2020). In the majority of cases, semi-structured interviewing does not provide a reliable source of information to support a concluding announcement for the selection of any degree programs. An unstructured interview also known as a non-directive interview that focuses on the concepts having no set standards and veto criteria about questions asked from the applicants. The interviewers made amorphous discussions and ask nor-determined questions from the interviewee. During interviews, the interviewers made natural conversation and asked open-ended questions that abruptly come into their minds (Prevett et al., 2021). The interview panel made it complicated to evaluate and categorized suitable applicants as they fewer provide factual information on the same questions (Walker et al., 2020).

The literature cites three main approaches to research interview; traditional, constructive, and activists approach. The traditional approach focuses on the researchers' role during the process of an interview that is being purported in the process of research (Holstein, \& Gubrium, 2004). It enhances the researchers need to pull for a strong practical relationship, having philosophical esteem in their thinking, suggestions, opinions, and perspectives (Agarwal, 2020; Rapport, 2020). The researchers are confident to speak with the interviewees while conducting the interviews. The traditional approach determined that the observer act as a storage area during the question and answering process of the interview. The researchers give the impression of nonverbal signs and signals; face impression, voice tone, stop, emotions, ups, and downs in voice, rhyming questioning, and nod (Bourdeau, 2000; Hall \& Howard, 2008). The constructive approach is based on the traditional imperative model of the interview having individual's aspects of verbalization and communication. The constructive approach focuses on the nature of dialogic discussion beneath the sympathy and empathy of research understanding (Harris \& Owen, 2007). The constructivists comprehend that understanding and position for information invention via strong teamwork play a significant role for the interviewee and 
the interviewer (Menon et al., 2020). The constructivists consider diverse approaches are the two-way mean making understanding for both of interviewee and the interviewer. They give an astonishingly little bit of attention to research meaning from the interviewee's perspective. Anything that transpires throughout the qualitative process significantly affects the interpretation of interviewees' behaviour (Ahmed et al., 2020; Fallon \& Brown, 2002; Frels, 2010). The activists approach to influence the interviewee's attitudes, behaviours, perceptions and, particularly for those who remain motionlessness, fewer participants and cooperative during the entire process, as it includes victims of shock and less supremacy of commands (Dreger et al., 2020) and victims of collaborative aggression (Menon et al., 2020; Geddes \& Andreasen, 2020; Rossman, \& Rallis, 2003). In the majority of situations, the interviewers take notice, especially for those individuals that are not listening clearly or have fewer participants. However, it is also dominant that after hearing the participants tone of voice is not similar as the research process is being conducted for the interviewees (Fallon, \& Brown, 2002). The researchers used the activists approach for the fast mode of data collection and are the worthwhile approach to complete assignments, projects, and theses (Bos-van den Hoek et al., 2021; Shahvaroughi et al., 2021).

An interview is an energetic, spirited, and self-motivated procedure designed by the authorities/researchers to obtained required information from the participants. It is an oral and face-to-face way of communication that occurs between the interviewer and the interviewee. Before conducting an interview, the participants are fully prepared for active, face-toface, oral, attitudinal, behavioural, and gestural conversations to acquire a prescribed position. To obtain admission/job an interview plays an essential role in students admission for acquiring graduate/undergraduate degree as well. When it is conducted with zeal and zest, the participants determine their hidden skills, expertise and enthusiastically try to meet admission requirements (Bußenius \& Harendza, 2021; Burr et al., 2021). During obtaining admission, institution management and faculty members conduct an interview to perceived applicants jesters, knowledge potential, communication skills, and physical appearance (Morris, 1999; Nelson et al., 2013). It is one of the common beliefs that students are entirely prepared themselves to face professionals, experts, and faculty members that make their critical analysis and select for the prescribed responsibilities. Literature reported that the authors globally explored dimensions of interviews in admission in Taiwan (Lin et al., 2021), in UK (Abell et al., 2021; Frost, 2021; Griffiths et al., 2021), in China (Weston, 2021), in India (Pal et al., 2021), in the USA (Ford et al., 2021; Hamidi et al., 2021; Inzana et al., 2021; Rosinger et al., 2021), in Germany (Bußenius \& Harendza, 2021) but there is hardly literature available in Pakistani educational institutions. Pakistani social scientists explored diverse aspects of interviews; gauge key information of the vaccinators (Zaidi et al., 2020), professionalism (Jalil et al., 2020), attitudes towards climate change (Khan et al., 2020), medical students perception about interview during admission (Haider et al., 2020), factors effect to opt remedies among COVID-19 patient (Raza et al., 2020) and women perception and experiences on stillbirth (Mcnojia et al., 2020).

\section{RATIONALE OF THE STUDY AND OBJECTIVE}

There is hardly any of the research conducted/recommended to explore university students perceptions about an interview conducted while getting admission in M.Phil and Ph.D. degree programs. Moreover, like other countries of the world, in Pakistani educational institutions, conducting an interview also work as a back-bone in which interviewers monitor the interviewees hidden potential, cognitive abilities, and dark aspects of the applicants' personality. To choose suitable students for admission, the university administration conducts a written test and an interview to get them to enroll. Faculty members select motivated, dynamic, and active students that play imperative in research and practices. This research is an attempt to explore the hidden aspects of the selected M.Phil and Ph.D. students enrolled to obtain their degree and contribute to the existing body of knowledge. The present study was designed to explore students perceptions about the role of an interview in the selection of M.Phil and Ph.D. students at the Institute of Education and Research, University of the Punjab, Lahore-Pakistan. The current was further extended to explore that how an interview is the best technique used to select M.Phil and Ph.D. students in the public sector University of Pakistan.

\section{Research objectives}

The researchers framed the following research objectives in this research

1. To explore students perceptions about the role of the interview during M.Phil admission at a public sector university of Pakistan.

2. To find out students perceptions about the role of the interview during Ph.D. admission at a public sector university of Pakistan.

\section{RESEARCH METHODOLOGY}

This study was qualitative, leading to the interpretivism paradigm. The planning of the qualitative research is superior for uncovering individual experiences, beliefs, and use of the expression in the real world (Polotskaia \& Savard, 2021; van Gerven, 2021; Vysotskaya et al., 2021). The supporters of interpretivism claim that time and contextual free generalization are the manifold constructed certainties that are neither wanted nor achievable (Frost, 2021; Hill \& Knox, 2021). The interpretation of these certainties is inductively produced from the data as the subjectivity of certainties strongly correlate with sources of truth (Berger, 2021; Erçetin \& Bisaso, 2021; Hanaba et al., 2021; Lune \& Berg, 2017; Silverman, 2020; Tesar, 2021). The applications of qualitative research enhance the flexibility of research design (Bryman, 2016; Frost, 2021), avoid the researchers predestined hypothesis potential (Bouncken et al., 2021; $\underline{\text { Creswell \& }}$ 
Creswell, 2018), provide options to interpret results/findings with depth and details (Lune \& Berg, 2017; Yin, 2017), stimulate respondents attitudes (Silverman, 2020) and insight towards phenomenon under discussion (Hennink et al., 2020; Hill \& Knox, 2021). Concerning the worth of the interviews in qualitative research design, the researchers planned the current research to explore students perceptions about the role of interviews during M.Phil and Ph.D. admission at the Institute of Education and Research, University of the Punjab, Lahore-Pakistan.

\section{The Populations of study}

The researchers discussed with some scholars, recently enrolled in M.Phil and Ph.D. degree programs at the institute of education and research, University of Punjab, regarding their perceptions about the role of interviews. The research participants showed their willingness to cooperate about their perception of the interview. On the other hand, most of the scholars were voluntarily willing to share their personal, managerial, and social experiences in writing form. Keeping in view students thoughts, the researchers decided to interpret students perceptions about the role of the interview during M.Phil and Ph.D. admission. Hence, all enrolled male and female students in M.Phil and Ph.D. in the institute of education and research, university of Punjab, Lahore-Pakistan comprised of a population of the study.

\section{The sample of the study}

The sample of the current research consists of five M.Phil and five Ph.D. students of both genders selected. The researchers purposively selected scholars who were voluntarily agreed to provide their perception for an interview during M.Phil and Ph.D. Admission. Most of the scholars were employees in public and private sector institutions and, others were running their educational institutions. They are excused because, due to jobs problems. Due to time and financial constraints the researchers feel some difficulties connecting with scholars in their classrooms. Finally, five male and five female students of M.Phil and Ph.D. programs were the participants of the current research.

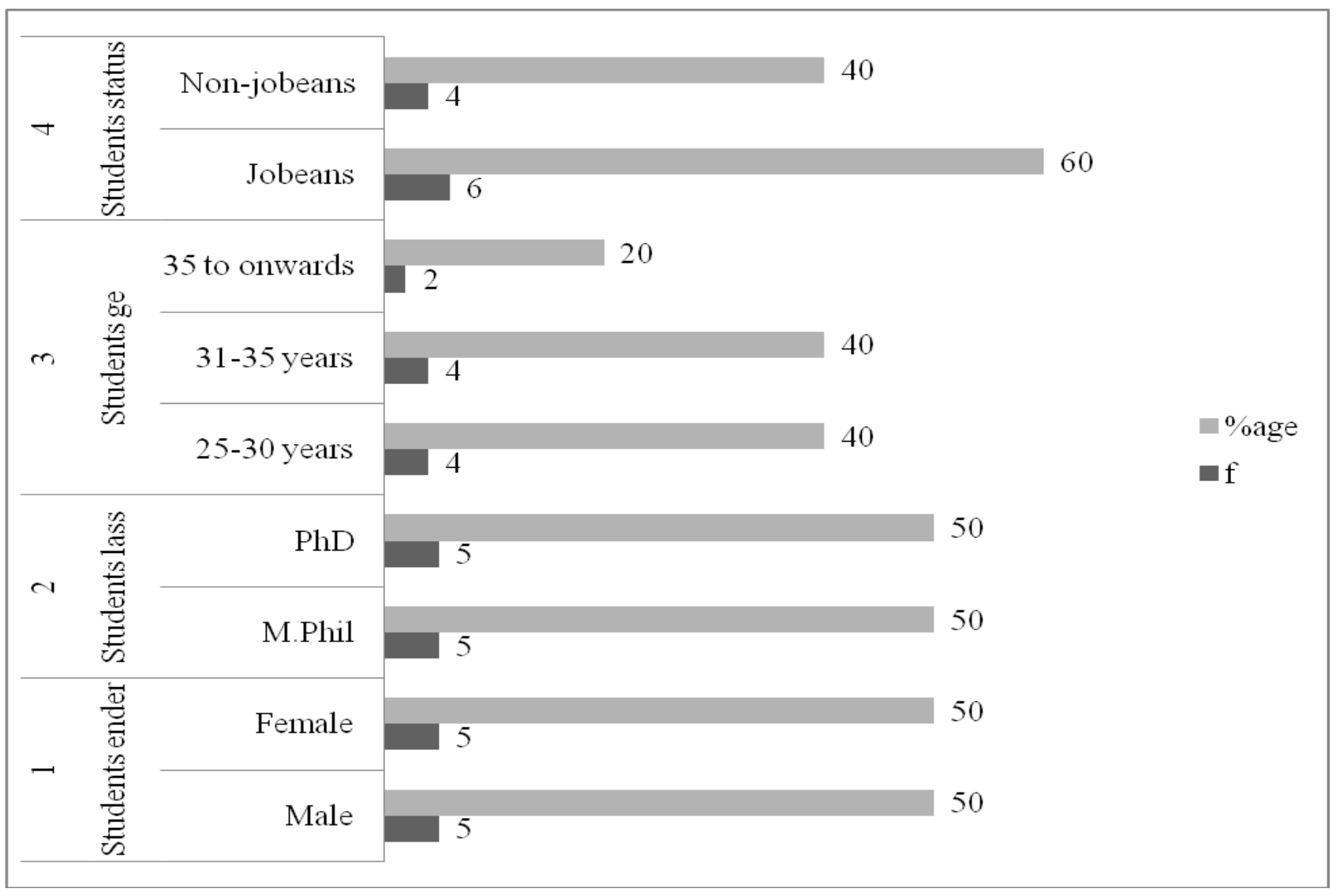

Figure 1: M.Phil and Ph.D students demographic information

\section{Instrumentation}

After literature of review, meetings with the experts and observational studies provide information about the tools, which used to collect the data. After a review of relevant literature, the researchers self-developed an interview protocol that was taken from the selected students of M.Phil and Ph.D. at the institute of education and research, university of the Punjab, Lahore. To make sure the truth or falsity of obtained data, the researchers used instrument validity techniques. Validity measures the truth or falsity of obtained data (Silverman, 2020). To assess the preferred contents/items (Ronkainen \& Wiltshire, 2021), the researchers made validation the instrument through expert visions. There were made important addition and deletion of items. The researchers fill note language difficulty/ambiguity of statements and any 
question for an explanation on any statements by respondents. The questions were improved in light of experts and respondents considerations. The researchers piloted a self-develop questionnaire on a small scale of the respondents that were not included in the final data collection procedures (Debbag et al., 2021). The pilot studies are the pivotal element of excellent study design (Lee \& Wessol, 2021) that provide logical insight (Coates, 2021) confers warning about instrument failure/success (Smith, 2021) and research protocols (McKenney \& Reeves, 2021). The researchers conducted a pilot to identify, remove/modify any ambiguous questions items. The first instrument consisted of 20-items. Items of the instrument were checked by experts to make sure the valid items as the instrument was prepared in the English version. An interview protocol was revised in the light of experts' opinions. Thus, the final instrument consisted of ten questions that were used to collect the data from the enrolled students of M.Phil and Ph.D. students at the Institute of Education and Research, University of the Punjab, Lahore-Punjab, Pakistan.

\section{Data Collection and Analysis Procedures}

The researchers themselves collected the data from the participants of the study. According to the feasibility of interviewees, the researchers signed a consent letter from the participants before the interview process focusing on ethical considerations; informed consent, anonymity, confidentiality, integrity, and no physical and psychological harm in case of the respondents volunteer participation. The literature stated that applications of ethical considerations are a pivotal aspect in the entire research process (Trevino \& Nelson, 2021) because they spread out information (Coe et al., 2021), shore up ethics and values (Smith, 2021), strengthen participants morale (Nguyen, 2021) and enhance mutual esteem of equality and equality (Thomas, 2021). After ensuring the ethical considerations, the researchers planned interview date, time, and place with participants. They recorded the interview of the participants in a voice recorder. It takes 20-25 minutes for each of the participants. For conducting the interviews, the researchers selected non-threatening and silent places; vacant classrooms, and libraries. Due to the hazard of noisy hindrance, it was less possible for the researchers to conduct the interviews in students' lounges and campus outdoors. After recording all the interviews, the researchers converted interviews into mp3 format. Once the researchers transferred the interviews, the authors generated themes for thematic analysis. The literature reported that thematic analysis is a foundational technique (Boudah, 2019; Fraenkel et al., 2019) commonly used for qualitative data analysis (Houser, 2019; Shafie, 2021) from valuable data (Samaden, 2021). By employing thematic analysis, the researchers identified, analyze, interpret and report themes of the data in rich detail (Babbie, 2020; Hennink et al., 2020; Silber-Varod et al., 2019). These themes were sort into categories for meaningful results (de Los Angeles Bacigalupe, 2020; Lune \& Berg, 2017; Yang et al., 2021). For smooth analysis of the results, the researchers applied thematic analysis techniques. After analysis of the data usage information, suggesting, conclusions, limitations of the research and, recommendations were made for further study purposes.

\section{Data Analysis and Results}

Question 1: What was the effect of your personality on the interview panel?

Three out of the ten interviewees stated that personality has a better effect during the interview. It impressed the interview panel. Three out of the ten interviews said that the dress and outlook of the interviewees could impress the interview panel. "One of the interviewees stated that personality has little effect on interview panel". Two out of ten interviewees said that personality ensures an imperative role on the interview panel during selection. One out of ten interviewees stated that personality plays a dramatic role on the interview panel. If they wear an attractive dress, the panel remains cheerful and communicates in a relaxed mood.

Question 2: What was your state of mind before the interview?

Six out of ten interviewees stated that before the interviews they were very much nervous because it is difficult to face 45 Professors at a time and gave their answers. They never face such a situation before. They were discussing the interview-related questions with each other. Four of ten interviewees were relaxed and fully confident that they had already faced many times such sort of situations. They had a little bit of command of their knowledge and have the ability to face panel. Two of the male and two of the female interviewee said that "they were nervous before interview time”.

Question 3: What was your bodily condition before the interview while admission?

Six out of ten interviewees confirmed that they were less relaxed before the interviewers. Their heartbeat was fast and continuously reciting some sort of Holy Ayat to make them relax. At the same time, four of ten interviewees cited that they were happy, energetic and, enthusiastic that they would enroll in higher degree programs in one of the public sector universities of Lahore-Pakistan. They were ready to face such type of situation among the panel. While four out of ten participants stated that they were physically relaxed before the interview panel. Two of the female interviewee said that they were very relaxed because they had a full grip on their content and pedagogical knowledge.

Question 4: Will you share the behaviour of the interview panel with the researchers?

Nine of the ten interviewees have in opinioned that the interviewer's gestures and, behaviour were cooperative with them. They were applying their soft-behavioural technique with me due to my knowledge-based and relevant answers. They were highly cooperative and supportive due to confidence. We were happy that they make us relaxed. When we 
entered the room, they were in a blissful mood. It was seeing that all were happy to see us. One of the ten interviewees stated that the interviewers showed some strict behaviour and made harsh communication with him. One of the male interviewees said that the interview panel was very strict with him due to my poor content knowledge and lack of confidence.

Question 5: What were you feeling about the place of interview environment?

Ten out of ten interviewees stated that while interviewing, the environment of the room was very comfortable. All sorts of facilities are there in the interviews room. They were sitting calm and facing a comfortable environment as it was a very hot day. There was no problem with water and electricity. One male and one of the female interviewees said that they were a little bit satisfied with the place where the interview was conducted.

Question 6: Why were you interested in getting admission in M.Phil/Ph.D. at the Institute of Education and Research, University of the Punjab, Lahore?

Six out of the ten interviewees stated that the institute of education and research, the University of Punjab, LahorePakistan is comprehensive in curricular and co-curricular facilities. There are national and foreign qualified staff members, open access to latest books, research journals, internet facilities, equipped computer labs, technologically skilled staff and, furnished libraries. It is the prestigious institute of Pakistan. Four of the ten interviewees cited that as we have already studied here, that's why we like its atmosphere and environment. This institute is enriched with professional and trained faculty members. One of the male interviewees said that he just wants to get a degree from this prominent institution.

Question 7: After interviewing, what were your impression regarding admission M.Phil/Ph.D. at Institute of Education and Research, University of the Punjab, Lahore?

Seven out of ten interviewees were fully confident that they will get admission to the Institute of Education and Research, University of the Punjab-Lahore because they had a good educational background as well as sound knowledge in their answers. During the interview, they satisfy the interviewing panel. Three of the ten interviewees were in doubt that there is much competition here in the Institute of Education and Research, University of the Punjab, LahorePakistan, and they do not know about their admission. One of the male interviewees said that "he was totally blanked about his impression regarding admission".

Question 8: Do you feel that you were asked relevant questions according to your field of study?

Nine out of ten interviewees stated that the interview panel asked relevant questions according to their field of study. Mostly were asked questions from their research work, they were passed in M.A or M.Phil interview panel also some question from subjects like assessment, philosophy, psychology, about their job. One of ten interviewees reported that I was asked some irrelevant questions like Economics that I never taught before. One male interviewee stated that "he was asked inappropriate and unconnected questions regarding his field/research work".

Question 9: What were the main reasons while getting admission to M.Phil/Ph.D. at Institute of Education and Research, University of the Punjab, Lahore?

Eight out of ten interviewees stated that they want to get a good-paying job which is why they get admission to the Institute of Education and Research, University of the Punjab, Lahore. They want to enhance their qualification because, in this current era, just an M.A degree has no value. One of ten interviewees confirmed that he wants to improve his knowledge, skills, and wants to be in touch with the Institute of Education and research, University of the Punjab, faculty members based on their knowledge. One of ten interviewees cited that he has got admission to the Institute of Education and Research, University of Punjab because I want to live in Lahore. Whenever I got admission to the Institute of Education and Research, University of Punjab, Lahore-Pakistan he will be allotted a hostel where I stay. One of the males and one of the female interviewees believed that forgetting per month qualification allowance, they have the intention to get admission to the Institute of Education and Research, University of the Punjab, Lahore, Pakistan.

Question 10: Anything more you want to disclose with me while interviewing before the interview panel?

Eight out of ten interviewees stated that there is nothing to share with you because the interviewers asked pertinent and suitable questions from the interviewees. Two of ten interviewees stated that the interview panel should be asked relevant questions as to their area of research to M.A or M.Phil level.

\section{DISCUSSION}

There are many ways to judge applicants performance in educational institutions (Bußenius \& Harendza, 2021). Research interview is one of the key tools used in qualitative research. It provides purposeful information about any of the applicants for the overall selection process in any degree program (Lopez et al., 1996; Mittenberg et al., 2000). Educational institutions entirely focused on the selection of appropriate candidates through conducting interviews (Ferguson et al., 2002). For this purpose, the interview panel grants a significant weight-age to graduate students at the minimal performance altitude. Interviews may enhance the process of selection for different types of programs (Kreiter 
et al., 2004; Pal et al., 2021). Usually, an interview has the values in most of the educational institutions into measuring applicants educational performance in terms of their personality, communication skills, and interpersonal factors (Geddes \& Andreasen, 2020; Griffiths et al., 2021; Harris \& Owen, 2007). A good environment and interview panel make cooperate with the interviewee and they feel relax and gave answers of more questions that is amazing. Findings of the current research revealed that students of the Institute of Education and Research, University of the Punjab-Lahore, Pakistan have better perceptions about the role of the interview conducted to measure M.Phil and Ph.D. students perceptions. Results of the current research are strongly associated with the findings of the study conducted by Salvatori (2001) whose findings revealed that an interview is an important tool that significantly enhances institutional performance. The interview panel selects dynamic, self-confident, and active participants for institutional better growth. The results of the current research are similar to the findings of the study framed by Hamidi et al. (2021) in the USA on a sample of 1,825 respondents to gauge students perception of interview performance. The results declared that male and female applicants age, race, and ethnicity have fewer influences on students overall interview situations. Furthermore, the results of the current research are congruent with the findings of researches conducted in the USA (Ford et al., 2021; Hamidi et al., 2021; Inzana et al., 2021; Rosinger et al., 2021), in China (Weston, 2021), in the UK (Abell et al., 2021; Frost, 2021; Griffiths et al., 2021) in Germany (Bußenius \& Harendza, 2021), in Taiwan (Lin et al., 2021) in India (Pal et al., 2021) whose findings revealed that interviews play an imperative role before selection of the participants for any job/admission. Applicants with job experience, grip on their knowledge, and who have been given interviews many times, have more chances in the selection of any interesting degree programs (Morris, 1999; Salvatori, 2001). There are facts that only structured interviews are more convincing (Postuma et al., 2002) as they are costly and time-consuming procedures (Fauber, 2006; Goho \& Backman, 2006).

\section{CONCLUSIONS}

An interview works as a back-bone in the entire selection process. It demands time, energy skills, and participants potential. When they are conducted smoothly, it long-lastly affects the selectee complete performance. They freely determine the participants' skills, potential, and future concerns. It re-opened applicants' potential that to what extent they have the potential to achieve goals. Focusing on the importance of interviews, the researchers structure the current research to perceive the interview role while getting admission for M.Phil and Ph.D. programs in one of the Public Sector University of the Punjab province of Pakistan. After ensuring the ethical considerations, the researchers collected the data from enrolled students through self-constructed interview protocols. The researchers collected the data from the students in regular classrooms and libraries through a voice recorder. The researchers transcribed recording for thematic analysis. The research results conclude that students have better perceptions about the role of an interview for getting admission in M.Phil and Ph.D. degree programs. An interviewer's panel of the Institute of Education and Research, University of the Punjab, Lahore, Punjab-Pakistan is playing a crucial role in the selection of M.Phil and Ph.D. scholars in admission. The results of the current research declared that during an interview, personality count, strong knowledge, students mental preparation, good-work experience, first-class grades and, proper grip on relevant fields are the main reasons to enroll in any of the institutes for getting a higher/research degree. The study recommended that (i) interview panel should be given sufficient time to the applicants so that it genuinely judges their abilities and knowledge, (ii) the interviewers may be asked relevant questions from the students, and (iii) the further researchers may conduct mixmethod research studies on a large sample and in public and private sector higher learning educational institutions.

\section{LIMITATIONS OF THE STUDY}

Applications of an interview play an imperative in the selection of appropriate participants for the suitable post. Every educational institution sets different criteria for selection in which great emphasis is given to the interviews. In qualitative research, conducting the interview is a hectic task as well. Therefore, the researchers limited the current research to one of the public sector universities of Lahore, Punjab-Pakistan. The authors have enriched experience of studentship and teaching at the Institute of Education and Research, University of Punjab, Lahore. That's why; it was easy for the authors to conduct research on M.Phil and Ph.D. students and collect the data from the participants. On the other hand, in most of the public and private sector educational institutions, students are less available and poorly provide their data for research purposes, although the researchers ensure ethical considerations.

\section{AUTHORS CONTRIBUTIONS}

The authors enthusiastically, voluntarily, vigorously, and considerably contributed to completing this research by performing various errands. Dr. Muhammad Adnan Maqbool presented the research idea, highlighted key aspects of the research methodology and, constructed interview protocol. He addressed the research objectives, logically interpreted the research results and wrote conclusions of the research. Dr. Aroona Hashmi wrote the abstract, introduction, made thematic analysis, main findings and application of the study. She critically formulated the discussions part and wrote conclusions in this regards. Dr. Mehboob Ul Hassan worked on the references part with true spirit and vigour. He crosschecked all references with prescribed journal format (APA 7th edition) and wrote limitations of the research with zeal and zest. He generated hyperlink of citations with the end references. Furthermore, he incorporated all necessary changes suggested by the reviewer(s). Dr. Fasiha Altaf collected the data from the respondents and did a hectic job in writing a comprehensive literature review. She analytically evaluated overall manuscript as well. 


\section{REFERENCES}

1. Abell, J. G., Lassale, C., Batty, G. D., \& Zaninotto, P. (2021). Risk factors for hospital admission after a fall: a prospective cohort study of community-dwelling older people. The Journals of Gerontology: Series A, 76(4), 666-674. https://doi.org/10.1093/gerona/glaa255

2. Adhabi, E., \& Anozie, C. B. (2017). Literature review for the type of interview in qualitative research. International Journal of Education, 9(3), 86-97. https://doi.org/10.5296/ije.v9i3.11483

3. Agarwal, V. (2020). The semi-structured interviewing method in a qualitative study examining complementary and alternative medicine providers' knowledge discourse. SAGE Publications Ltd. https://doi.org/10.4135/9 781529715989

4. Ahmed, M. S., Khan, S., Hsan, K., Sen, L. C., Yunus, F. M., \& Griffiths, M. D. (2020). Factors affecting sleep quality among the university students in Bangladesh: A cross-sectional structured interview study. Sleep and Vigilance, 4(2), 177-184. https://doi.org/10.1007/s41782-020-00106-4

5. Babbie, E. R. (2020). The practise of social research. Cengage learning.

6. Bakker, E. J., Verhaegh, K. J., Kox, J. H., van der Beek, A. J., Boot, C. R., Roelofs, P. D., \& Francke, A. L. (2019). Late dropout from nursing education: An interview study of nursing students' experiences and reasons. Nurse Education in Practice, 39, 17-25. https://doi.org/10.1016/j.nepr.2019.07.005

7. Beitin, B. K. (2008). Qualitative research in marriage and family therapy: Who is in the interview? Contemporary Family Therapy, 30(1), 48-58. https://doi.org/10.1007/s10591-007-9054-y

8. Berger, M. S. (2021). Shifting paradigms in Islamic higher education in Europe: The case study of Leiden University. Religions, 12(1), 63. https://doi.org/10.3390/rel12010063

9. Bos-van den Hoek, D. W., Thodé, M., Jongerden, I. P., Van Laarhoven, H. W., Smets, E. M., Tange, D., ... \& Pasman, H. R. (2021). The role of hospital nurses in shared decision-making about life-prolonging treatment: A qualitative interview study. Journal of Advanced Nursing, 77(1), 296-307. https://doi.org/10.1111/jan.14549

10. Boudah, D. J. (2019). Conducting educational research: Guide to completing a thesis, Dissertation, or action research project. Sage Publications.

11. Bouncken, R. B., Qiu, Y., Sinkovics, N., \& Kürsten, W. (2021). Qualitative research: extending the range with flexible pattern matching. Review of Managerial Science, 15(2), 251-273. https://doi.org/10.1007/s11846-021$\underline{00451-2}$

12. Bourdage, J. S., Schmidt, J., Wiltshire, J., Nguyen, B., \& Lee, K. (2020). Personality, interview performance, and the mediating role of impression management. Journal of Occupational and Organizational Psychology, 93(3), 556-577. https://doi.org/10.1111/joop.12304

13. Bourdeau, B. (2000). Dual relationships in qualitative research. The Qualitative Report, 4(3), 1-6. https://doi.org/10.46743/2160-3715/2000.2081

14. Bryman, A. (2016). Social research methods (5th ed.). Oxford: Oxford University Press.

15. Burr, O., Berry, A., Joule, N., \& Rayman, G. (2021). Inpatient diabetes care during the COVID-19 pandemic: A Diabetes UK rapid review of healthcare professionals' experiences using semi-structured interviews. Diabetic Medicine, 38(1), e14442. https://doi.org/10.1111/dme.14442

16. Bußenius, L., \& Harendza, S. (2021). Are different medical school admission tests associated with the outcomes of a simulation-based OSCE? BMC Medical Education, 21(1), 1-8. https://doi.org/10.1186/s12909021-02703-X

17. Canagasuriam, D., \& Roulin, N. (2021). The effect of organizational culture on faking in the job interview. Personnel Assessment and Decisions, 7(1), 83-93. https://doi.org/10.25035/pad.2021.01.008

18. Coates, A. (2021). The prevalence of philosophical assumptions is described in mixed methods research in education. Journal of Mixed Methods Research, 15(2), 171-189. https://doi.org/10.1177/1558689820958210

19. Coe, R., Waring, M., Hedges, L. V., \& Ashley, L. D. (2021). Research methods and methodologies in education. Sage.

20. Creswell, J. W., \& Creswell, J. D. (2018). Research design: Qualitative, quantitative, and mixed methods approach (5th ed.). Sage.

21. de los Ángeles Bacigalupe, M. (2020). Qualitative dominant mixed methods research: Studying stigma in people with Parkinson's Disease. SAGE Publications Ltd. https://doi.org/10.4135/9781529742756

22. Debbag, M., Cukurbasi, B., \& Fidan, M. (2021). Use of digital mind maps in technology education: a pilot study with pre-service science teachers. Informatics in Education, 20(1), 47-68. https://doi.org/10.15388/in fedu. 2021.03

23. Deterding, N. M., \& Waters, M. C. (2021). Flexible coding of in-depth interviews: A twenty-first-century approach. Sociological Methods \& Research, 50(2), 708-739. https://doi.org/10.1177/0049124118799377

24. Di Pierro, R., Gargiulo, I., Poggi, A., Madeddu, F., \& Preti, E. (2020). The level of personality functioning scale applied to clinical material from the Structured interview of personality organization (STIPO): Utility in detecting personality pathology. Journal of Personality Disorders, 34(Supplement C), 62-76. https://doi.org/10.1521/pedi_2020_34_472 
25. Dreger, F. A., de Winter, J. C., \& Happee, R. (2020). How do drivers merge heavy goods vehicles onto freeways? A semi-structured interview unveiling needs for communication and support. Cognition, Technology \& Work, 22(4), 825-842. https://doi.org/10.1007/s10111-019-00601-3

26. Erçetin, Ş. Ş., \& Bisaso, S. M. (2021). The influence of changing paradigms on educational management and school administration. In Research Anthology on Preparing School Administrators to Lead Quality Education Programs (pp. 128-141). IGI Global. https://doi.org/10.4018/978-1-7998-3438-0.ch008

27. Fallon, G., \& Brown, R. B. (2002). Focusing on focus groups: Lessons form a research project involving a Bangladeshi community. Qualitative Research, 2(2), 195-208. https://doi.org/10.1177/146879410200200204

28. Fauber, R. L. (2006). Graduate admissions in clinical psychology: Observations on the present and thoughts on the future. Clinical Psychology, Science and Practice, 13, 227-234. https://doi.org/10.1111/j.14682850.2006.00029.x

29. Ferguson, E., James, D., \& Madeley, F. (2002). Factors associated with success in medical school: Systematic review of the literature. British Medical Journal, 324, 952-957. https://doi.org/10.1136/bmj.324.7343.952

30. Ford, K. S., Rosinger, K. O., \& Zhu, Q. (2021). Consolidation of class advantages in the wake of the great recession: University enrollments, educational opportunity and stratification. Research in Higher Education, 127. https://doi.org/10.1007/s11162-021-09624-0

31. Fraenkel, J. R., Wallen, N. E., \& Hyun, H., H. (2019). The nature of qualitative research. How to design and evaluate research in education (10th ed.). McGraw Hill.

32. Frels, R. K. (2010). The experiences and perceptions of selected mentors: An exploratory study of the dyadic relationship in school-based mentoring. Unpublished doctoral dissertation, Sam Houston State University, Huntsville, TX, USA.

33. Frost, D. M., Hammack, P. L., Wilson, B. D., Russell, S. T., Lightfoot, M., \& Meyer, I. H. (2020). The qualitative interview in psychology and the study of social change: Sexual identity development, minority stress, and health in the study of the generation. Qualitative Psychology, 7(3), 245-266. https://doi.org/10.1037/qup0000148

34. Frost, N. (2021). Qualitative Research Methods in Psychology: Combining Core Approaches. McGraw-Hill Education.

35. Geddes, J. R., \& Andreasen, N. C. (2020). New Oxford textbook of psychiatry. Oxford University Press. https://doi.org/10.1093/med/9780198713005.001.0001

36. Goho, J., \& Blackman, A. (2006). The effectiveness of academic admission interviews: An exploratory metaanalysis. Medical Teaching, 28(4), 335-340. https://doi.org/10.1080/01421590600603418

37. Griffiths, F., Svantesson, M., Bassford, C., Dale, J., Blake, C., McCreedy, A., \& Slowther, A. M. (2021). Decision-making around admission to intensive care in the UK pre-COVID-19: a multicentre ethnographic study. Anaesthesia, 76(4), 489-499. https://doi.org/10.1111/anae.15272

38. Haider, S. I., Bari, M. F., \& Ijaz, S. (2020). Using multiple mini-interviews for students' admissions in Pakistan: a pilot study. Advances in Medical Education and Practice, 11, 179-185. https://doi.org/10.2147/AM EP.S246285

39. Hall, B., \& Howard, K. (2008). A synergistic approach: Conducting mixed methods research with typological and systemic design considerations. Journal of Mixed Methods Research, 2, 248-269. https://doi.org/10.117 7/1558689808314622

40. Hamidi, Z., Durning, S. J., Torre, D., Liotta, R., \& Dong, T. (2021). Do interviews influence admission decisions? An empirical analysis from an institution. Military Medicine, 186(3), 426-436. https://doi.org/10.1093/milmed/usaa477

41. Hanaba, S., Mysechko, O., \& Bloshchynskyi, I. (2021). Changing the educational paradigm in the postpandemic world: Possibilities and risks of artificial intelligence using. Broad Research in Artificial Intelligence and Neuroscience, 11(2Sup1), 48-55. https://doi.org/10.18662/brain/11.2Sup1/93

42. Harris, S., \& Owen, C. (2007). Discerning quality: Using the multiple mini-interview in student selection for the Australian national university medical school. Medical Education, 41, 234-241. https://doi.org/10.1111/j.1 365-2929.2007.02682.x

43. Heimann, A. L., Ingold, P. V., \& Kleinmann, M. (2020). Tell us about your leadership style: A structured interview approach for assessing leadership behaviour constructs. The Leadership Quarterly, 31(4), 101364. https://doi.org/10.1016/j.leaqua.2019.101364

44. Hennink, M., Hutter, I., \& Bailey, A. (2020). Qualitative research methods. Sage.

45. Hewitt, P. L., Chen, C., Smith, M. M., Zhang, L., Habke, M., Flett, G. L., \& Mikail, S. F. (2021). Patient perfectionism and clinician impression formation during an initial interview. Psychology and Psychotherapy: Theory, Research and Practice, 94(1), 45-62. https://doi.org/10.1111/papt.12266

46. Hill, C. E., \& Knox, S. (2021). Essentials of consensual qualitative research. American Psychological Association. https://doi.org/10.1037/0000215-000

47. Ho, J. L., Powell, D. M., \& Stanley, D. J. (2021). The relation between deceptive impression management and employment interview ratings: A meta-analysis. Canadian Journal of Behavioural Science, 53(2), 164174. https://doi.org/10.1037/cbs0000223 
48. Holstein, J. A., \& Gubrium, J. F. (2004). The active interview. In D. Silverman (Ed.), Qualitative research: Theory, method, and practice (pp. 140-161). Sage.

49. Holt, G., \& Hughes, D. (2021). A study using a semi-structured interview and Delphi survey to explore the barriers and enabling factors that influence access and utilisation of weight management services for people living with morbid obesity: A patient and professional perspective. Journal of Human Nutrition and Dietetics, 34(1), 215-223. https://doi.org/10.1111/jhn.12832

50. Houser, R. A. (2019). Counselling and educational research: Evaluation and application. Sage Publications.

51. Hsueh, L., Werntz, A., Hobaica, S., Owens, S. A., Lumley, M. A., \& Washburn, J. J. (2021). Clinical psychology PhD students admission experiences: Implications for recruiting racial/ethnic minority and LGBTQ students. Journal of Clinical Psychology, 77(1), 105-120. https://doi.org/10.1002/jclp.23074

52. Inzana, K. D., Vanderstichel, R., \& Newman, S. J. (2021). Virtual multiple mini-interviews for veterinary admissions. Journal of Veterinary Medical Education, e20200107. https://doi.org/10.3138/jvme-2020-0107

53. Isham, L., Griffith, L., Boylan, A. M., Hicks, A., Wilson, N., Byrne, R., ... \& Freeman, D. (2021). Understanding, treating and renaming grandiose delusions: A qualitative study. Psychology and Psychotherapy: Theory, Research and Practice, 94(1), 119-140.

54. Jalil, A., Mahmood, Q. K., \& Fischer, F. (2020). Young medical doctors' perspectives on professionalism: a qualitative study conducted in public hospitals in Pakistan. BMC Health Services Research, 20(1), 1-10. https://doi.org/10.1186/s12913-020-05681-w

55. Khan, I., Lei, H., Shah, I. A., Ali, I., Khan, I., Muhammad, I., ... \& Javed, T. (2020). Farm households' risk perception, attitude and adaptation strategies in dealing with climate change: Promise and perils from rural Pakistan. Land Use Policy, 91(c), 104395. https://doi.org/10.1016/j.landusepol.2019.104395

56. Krajewski, H. T., Goffin, R. D., McCarthy, J. M., Rothstein, M. G., \& Johnston, N. (2006). Comparing the validity of structured interviews for managerial-level employees: should we look to the past or focus on the future? Journal of Occupational and Organizational Psychology, 79(3), 411-432. https://doi.org/10.1348/096 $\underline{317905 X 68790}$

57. Kreiter, C. D., Yin, P., Solow, C., \& Brennan, R. L. (2004). Investigating the reliability of the medical school admissions interview. Advances in Health Sciences Education, Theory and Practice, 9(2), 147-159. https://doi.org/10.1023/B:AHSE.0000027464.22411.0f

58. Kwan, Y., Choi, S., \& Eom, T. R. (2021). Development of a structured interview to explore interpersonal schema of older adults living alone based on autobiographical memory. International Journal of Environmental Research and Public Health, 18(5), 2316. https://doi.org/10.3390/ijerph18052316

59. Lee, K. C., \& Wessol, J. L. (2021). Pilot Studies: Considerations in nursing education. Nurse Educator, 46(1), 12-13. https://doi.org/10.1097/NNE.0000000000000868

60. Li, Q. (2021). Computational thinking and teacher education: An expert interview study. Human Behavior and Emerging Technologies, 3(2), 324-338. https://doi.org/10.1002/hbe2.224

61. Lin, C. H., Chen, M. H., Tsai, T. C., \& Huang, W. J. (2021). Difference in demographics and motivation to study medicine with respect to medical students' channel of admission: A national study. Medical Teacher, 1-6. https://doi.org/10.1080/0142159X.2021.1902965

62. Lopez, S. J., Oehlert, M. E., \& Moberly, R. L. (1996). Selection criteria for American Psychological Association-accredited internship programs: A survey of training directors. Professional Psychology: Research and Practice, 27(5), 518-520. https://doi.org/10.1037/0735-7028.27.5.518

63. Lune, H., \& Berg, B. L. (2017). Qualitative research methods for the social sciences. Pearson.

64. McKenney, S., \& Reeves, T. C. (2021). Educational design research: Portraying, conducting, and enhancing productive scholarship. Medical Education, 55(1), 82-92. https://doi.org/10.1111/medu.14280

65. Mcnojia, S. Z., Saleem, S., Feroz, A., Khan, K. S., Naqvi, F., Tikmani, S. S., ... \& Goldenberg, R. L. (2020). Exploring women and traditional birth attendants' perceptions and experiences of stillbirths in district Thatta, Sindh, Pakistan: A qualitative study. Reproductive Health, 17(1), 1-11. https://doi.org/10.1186/s12978-020$\underline{0852-0}$

66. Melinder, A., Magnusson, M., \& Gilstrap, L. L. (2021). What is a child-appropriate interview? Interaction between child witnesses and police officers. International Journal on Child Maltreatment: Research, Policy and Practice, 3(4), 369-392. https://doi.org/10.1007/s42448-020-00052-8

67. Menon, V., Varadharajan, N., Bascarane, S., Subramanian, K., Mukherjee, M. P., \& Kattimani, S. (2020). Psychological autopsy: Overview of Indian evidence, best practice elements, and a semi-structured interview guide. Indian Journal of Psychiatry,62(6), 631-643. https://doi.org/10.4103/psychiatry.IndianJP sychiatry $331 \_0$

68. Mittenberg, W., Petersen, R. S., Cooper, J. T., Strauman, S., \& Essig, S. M. (2000). Selection criteria for clinical neuropsychology internships. Clinical Neuropsychologist, 14(1), 1-6. https://doi.org/10.1076/13854046(200002)14:1;1-8;FT001

69. Mohamadi, S., Garkaz, O., Mousavi, S. A., Keramat, A., Goli, S., \& Motaghi, Z. (2021). The effect of the motivational interview on puberty knowledge and practice among adolescent girls. Nursing and Midwifery Studies, 10(1), 13-19. https://doi.org/10.4103/nms.nms_4_20 
70. Morris, J. G. (1999). The value and role of the interview in the student admissions process: a review. Medical Teacher, 21(5), 473-481. https://doi.org/10.1080/01421599979149

71. Nelson, J. A., Onwuegbuzie, A. J., Wines, L. A., \& Frels, R. K. (2013). The therapeutic interview process in qualitative research studies. The Qualitative Report, 18(40), 1-17.

72. Nguyen, N. (2021). Rethinking activist educational research: definitions, methodologies, and ethics. Critical Studies in Education, 62(2), 258-273. https://doi.org/10.1080/17508487.2019.1630458

73. Onwuegbuzie, A. J., \& Leech, N. L., \& Collins, K. M. T. (2008). Interviewing the interpretive researcher: A method for addressing the crises of representation, legitimation, and praxis. International Journal of Qualitative Methods, 7(4), 1-17. https://doi.org/10.1177/160940690800700401

74. Pachana, N. A., O’Donovan, A., \& Helmes, E. (2006). Australian clinical psychology training program directors survey. Australian Psychologist, 41(3), 168-178. https://doi.org/10.1080/00050060600820644

75. Pal, R., Yadav, U., Verma, A., \& Bhadada, S. K. (2021). Awareness regarding COVID-19 and problems being faced by young adults with type 1 diabetes mellitus amid nationwide lockdown in India: A qualitative interview study. Primary care diabetes, 15(1), 10-15. https://doi.org/10.1016/j.pcd.2020.07.001

76. Polotskaia, E., \& Savard, A. (2021). Some multiplicative structures in elementary education: a view from relational paradigm. Educational Studies in Mathematics, 106(3), 447-469. https://doi.org/10.1007/s10649-02009979-8

77. Postuma, R. A., Morgeson, F. P., \& Campion, M. A. (2002). Beyond employment interview validity: A comprehensive narrative review of recent research and trends over time. Personnel Psychology, 55(1), 1-81. https://doi.org/10.1111/j.1744-6570.2002.tb00103.x

78. Prevett, P. S., Black, L., Hernandez-Martinez, P., Pampaka, M., \& Williams, J. (2021). Integrating thematic analysis with cluster analysis of unstructured interview datasets: an evaluative case study of an inquiry into values and approaches to learning mathematics. International Journal of Research \& Method in Education, 44(3), 273-286. https://doi.org/10.1080/1743727X.2020.1785416

79. Rad, D., \& Balas, V. E. (2020). A Novel fuzzy scoring approach of behavioural interviews in personnel selection. Broad Research in Artificial Intelligence and Neuroscience, 11(2), 178-188. https://doi.org/10.18662/brain/11.2/81

80. Rapport, N. (2020). The Interview as a form of talking-partnership: Dialectical, focussed, ambiguous, special. In The Interview (pp. 53-68). Routledge. https://doi.org/10.4324/9781003087014-3

81. Raza, A., Matloob, S., Rahim, N. F. A., Halim, H. A., Khattak, A., \& Ahmed, N. H. (2020). Factors impeding health-care professionals to effectively treat Corona Virus disease 2019 patients in Pakistan: A qualitative investigation. Frontiers in Psychology, 11(572450). https://doi.org/10.3389/fpsyg.2020.572450

82. Robinson, O. C. (2014). Sampling in interview-based qualitative research: A theoretical and practical guide. Qualitative Research in Psychology, 11(1), 25-41. https://doi.org/10.1080/14780887.2013.801543

83. Ronkainen, N. J., \& Wiltshire, G. (2021). Rethinking validity in qualitative sport and exercise psychology research: A realist perspective. International Journal of Sport and Exercise Psychology, 19(1), 13-28. https://doi.org/10.1080/1612197X.2019.1637363

84. Rosinger, K. O., Ford, K. S., \& Choi, J. (2021). The role of selective college admissions criteria in interrupting or reproducing racial and economic inequities. The Journal of Higher Education,92(1), 31-55. https://doi.org/10.1080/00221546.2020.1795504

85. Rossman, G., \& Rallis, S. (2003). Learning in the field: An introduction to qualitative research. Thousand Oaks, CA: Sage.

86. Rotteveel, A. H., Lambooij, M. S., van de Rijt, J. J., van Exel, J., Moons, K. G., \& de Wit, G. A. (2021). What influences the outcome of active disinvestment processes in healthcare? A qualitative interview study on five recent cases of active disinvestment. BMC Health Services Research, 21(1), 1-12. https://doi.org/10.1186/s1 2913-021-06298-3

87. Roulston, K. (2010). Considering quality in qualitative interviewing. Qualitative Research, 10(2), 199-228. https://doi.org/10.1177/1468794109356739

88. Salvatori, P. (2001). Reliability and validity of admissions tools used to select students for the health professions. Advances in Health Sciences Education, 6(2), 159-175. https://doi.org/10.1023/A:1011489618208

89. Samaden, I. S. B. (2021). Time element in the construct of special education teacher workload in Malaysia. Turkish Journal of Computer and Mathematics Education, 12(11), 5141-5145.

90. Schmidt, F. L., \& Hunter, J. E. (1998). The validity and utility of selection methods in personnel psychology: Practical and theoretical implications of 85 years of research findings. Psychological Bulletin, 124(2), 262-274. https://doi.org/10.1037/0033-2909.124.2.262

91. Schudlik, K., Reinhard, M. A., \& Müller, P. (2021). Prepared to fake? The relationship between applicants' job interview preparation and faking. International Journal of Selection and Assessment, 29(1), 29-54. https://doi.org/10.1111/ijsa.12317

92. Seldman, I. E. (2012). Interviewing as qualitative research (4th ed.). Teachers College Press.

93. Shafie, A. S. B. (2021). Elements of safety in job satisfaction of special education teachers in Malaysia. Turkish Journal of Computer and Mathematics Education, 12(11), 5274-5278. 
94. Shahvaroughi, A., Ehsan, H. B., Hatami, J., Monajem, A., \& Paulo, R. M. (2021). Testing a modified cognitive interview with category clustering recall in Iran. Applied Cognitive Psychology, 35(1), 148-159. https://doi.org/10.1002/acp.3747

95. Silber-Varod, V., Eshet-Alkalai, Y., \& Geri, N. (2019). Tracing research trends of 21 st-century learning skills. British Journal of Educational Technology, 50(6), 3099-3118. https://doi.org/10.1111/bjet.12753

96. Silverman, D. (2020). Qualitative research. Sage Publications Limited.

97. Smith, L. T. (2021). Decolonizing methodologies: Research and indigenous peoples. Zed Books Ltd.

98. Smith, M. J., Smith, J. D., Jordan, N., Sherwood, K., McRobert, E., Ross, B., ... \& Atkins, M. S. (2021). Virtual reality job interview training in transition Services: Results of a single-arm, Noncontrolled effectivenessimplementation Hybrid trial. Journal of Special Education Technology, 36(1), 3-17. https://doi.org/10.117 7/0162643420960093

99. Sonnentag, S., Stephan, U., Wendsche, J., de Bloom, J., Syrek, C., \& Vahle-Hinz, T. (2021). Recovery in occupational health psychology and human resource management research: An Interview with Prof. Sabine Sonnentag and Prof. UTE Stephan. German Journal of Human Resource Management, 35(2), 274-281. https://doi.org/10.1177/23970022211004599

100.Tesar, M. (2021). "Philosophy as a method": Tracing the histories of intersections of "philosophy,"“methodology," and "education. Qualitative Inquiry, 27(5), 544-553. https://doi.org/10.1177/ 1077800420934144

101. Thomas, G. (2021). How to do your case study. Sage.

102.Tingaz, E. O. (2021). The psychological impact of COVID-19 pandemic on elite athletes, management strategies and post-pandemic performance expectations: a semi structured interview study. International Journal of Educational Research and Innovation, 15, 73-81. https://doi.org/10.46661/ijeri.4863

103.Trevino, L. K., \& Nelson, K. A. (2021). Managing business ethics: Straight talk about how to do it right. John Wiley \& Sons.

104.van Gerven, E. (2021). Educational paradigm shifts and the effects on educating gifted students in the Netherlands and Flanders. Journal for the Education of the Gifted,44(2), 171-200. https://doi.org/10.11 77/01623532211001452

105. Vysotskaya, E., Lobanova, A., Rekhtman, I., \& Yanishevskaya, M. (2021). The challenge of proportion: does it require rethinking of the measurement paradigm? Educational Studies in Mathematics, 106(3), 429-446. https://doi.org/10.1007/s10649-020-09987-8

106.Walker, R. C., Tong, A., Howard, K., \& Palmer, S. C. (2020). Clinicians' experiences with remote patient monitoring in peritoneal dialysis: A semi-structured interview study. Peritoneal Dialysis International, 40(2), 202-208. https://doi.org/10.1177/0896860819887638

107.Warren, C. (2002). Qualitative interviewing. In J. Gubrium \& J. Holstein (Eds.), Handbook of interview research: Context and method (pp. 83-102). Sage. https://doi.org/10.4135/9781412973588.n7

108. Weston, D. (2021). Gatekeeping and linguistic capital: A case study of the Cambridge university undergraduate admissions interview. Journal of Pragmatics, 176, 137-149. https://doi.org/10.1016/j.pragma.2021.02.002

109. Yang, A., Fernando, S., Tighe, J., Monica, O., Morphet, J., \& Kumar, A. (2021). Impact of an interprofessional surgical skills workshop on undergraduate medical and nursing student interest in a career in surgery: A thematic analysis. Journal of Surgical Education, 78(3), 905-913. https://doi.org/10.1016/j.jsurg.2020.09.014

110. Yin, R. K. (2017). Case study research: Design and methods (6th ed.). Sage.

111.Yusoff, M. S. B. (2019). Multiple mini-interviews as an admission tool in higher education: Insights from a systematic review. Journal of Taibah University Medical Sciences, 14(3), 203-240. https://doi.org/10.101 6/j.jtumed.2019.03.006

112.Zaidi, S., Shaikh, S. A., Sayani, S., Kazi, A. M., Khoja, A., Hussain, S. S., \& Najmi, R. (2020). Operability, acceptability, and usefulness of a mobile app to track routine immunization performance in rural Pakistan: interview study among vaccinators and key informants. JMIR Mhealth Uhealth, 8(2), e16081. https://doi.org/10.2196/16081 